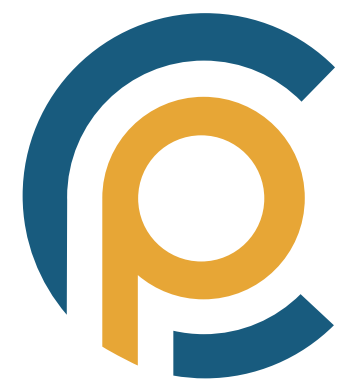

\title{
Teatro y educación en la Ley General de 1970. Avances y retrocesos
}

\author{
Theatre and education in the 1970 General Law. \\ Advances and Setbacks
}

Recibido: 20/09/2020 | Revisado: 21/10/2020 | Aceptado: 05/11/2020 | Publicado: 22/12/2020

\author{
Manuel F. Vieites \\ ESAD de Galicia / Universidad de Vigo (España) \\ mvieites@uvigo.es \\ https://orcid.org/0000-0003-4372-6234
}

\begin{abstract}
Resumen: Ley General de Educación, promulgada en 1970, supone la primera tentativa de normalización y regulación de la educación teatral en España, en toda su diversidad. Por un lado, la Ley sitúa la educación artística, y con una orientación expresiva, en la agenda curricular de la educación general, lo que permitirá mostrar el potencial pedagógico de un conjunto de procedimientos de carácter dramático y teatral, confirmar su legitimidad educativa, y generar desarrollos importantes en las culturas empírica y científica. Por otro, la norma mantiene y defiende el carácter superior de los estudios de Arte Dramático, y su incorporación a la Universidad, en sintonía con lo que había sido su estatuto académico desde la Ley Moyano de 1857 y con transiciones similares que se estaban produciendo en toda Europa en la misma dirección. Con este trabajo, escrito desde un análisis de la normativa derivada de la aplicación de la LGE y de una revisión de literatura generada, mostramos los avances que fomentó, y que otras normas posteriores no siempre consolidaron, lo que supuso retrocesos importantes que nos trasladan problemáticas que cincuenta años después aún esperan ser resueltas. Al mismo tiempo mostramos algunas líneas de trabajo especialmente relevantes en la construcción de la Historia de la Educación teatral y de la Historia de la Pedagogía Teatral en España.
\end{abstract}

Palabras clave: educación artística, currículo, expresión, teatro, universidad.
Abstract: The General Education Act, enacted in 1970, appears as the first attempt to regulate Theatre Education in Spain, considering all its diversity. On the one hand, this new law places Art Education in the General Education curriculum and provides it an expressive approach. This showed the pedagogical potential of different procedures of dramatic and theatrical nature, confirmed its educational legitimacy, and produced developments in both their empirical and scientific cultures. On the other hand, the Act stated and promoted the integration of Schools of Dramatic Art and its courses in the university, in tune with what had been its status since 1857 with the Moyano Education Act, and with similar transitions taking place in Europe in the same direction. This paper, which has been written after an analysis of the educational norms derived from the application of the Act, combined with a review of the literature generated at that period, shows the advances the change enhanced. Also, reveals that later Educational Acts were not always confirmed or consolidated, and that provoked important setbacks causing persistent of problems. Also, further research lines particularly relevant in the development of the further research lines particularly relevant in the development of the History of Theatre Education and also of the History of Theatre Pedagogy in Spain have been provided.

Keywords: art education, curriculum, expression, theatre, university. 
En el proceso de regularización de la educación teatral, la Ley General de Educación (LGE) abre caminos que desarrolla posteriormente la Ley de Ordenación General del Sistema Educativo (LOGSE), aunque algunos estén aún por recorrer. Así, de Preescolar al Bachillerato, la LGE, introduce, por tímida que fuese la propuesta, áreas de actividad (pantomimas, dramatización, teatro guiñol, lecturas dramatizadas), que resultan novedosas, y se dirá que en la escuela de finales de los sesenta muy poco se hacía en ese campo, y que "el Ministerio de Educación consagra en el papelín oficial lo que a nivel de calle es inexistente, cuando suele ocurrir lo contrario" (Amich et al., 1983, p.46).

La LGE (MEC, 1970a) introduce matices modernizadores, como el concepto de "expresión", y los "principios generales" de la Reforma, contenidos en su Libro Blanco (Bases para una política educativa), señalan que la enseñanza "partirá de experiencias significativas, subrayando la actividad práctica, la creación y la espontaneidad innovadora" (MEC, 1969, p.207). La propuesta, sobre el papel, suponía un cambio de rumbo, siendo España un país especialmente refractario a determinadas innovaciones curriculares, y no hablamos del teatro escolar, presente en numerosos centros educativos (Cervera y Guirau, 1972), sino de la educación teatral general. Como escribía Tejerina, "la relación entre teatro y la escuela es bastante más deficitaria que la de los países de nuestro entorno" (1994, p.267), y más entre teatro y aula. Las culturas científica, empírica y normativa propias a la educación teatral, tenían, hasta ese momento en España, relevancia escasa, salvo excepciones, como los tratados de declamación publicados desde finales del XVIII a principios del XX (Rubio Jiménez, 2002), la persistencia del teatro escolar (Cervera, 1982), o el desarrollo de la educación teatral superior (Granda, 1994; Graells, 1999; Soria Tomás, 2010). Por ello, será la LGE la que venga a paliar el déficit señalado, con dos grandes novedades.

En primer lugar, en la educación general, se promueven "áreas de aprendizaje, evitando la fragmentación en asignaturas de difícil armonización" (MEC, 1970b, p.2), como las denominadas "áreas de expresión" y "áreas de experiencia". En las Orientaciones Pedagógicas para la Educación General y en relación al educando se afirma que "lo fundamental en su formación será el desenvolvimiento de su capacidad de comunicación, es decir, la capacidad de expresión y comprensión, y entonces la actividad educativa fundamental debe apoyarse en la actividad expresiva" (MEC, 1970b, p.6). Por ahí asoma una tímida incorporación de la educación teatral al currículo de la educación general, a través de la dramatización, un procedimiento que tendrá trascendencia creciente. En segundo lugar, el carácter "global" de la Reforma busca soluciones plausibles a cuestiones de ordenación educativa en las enseñanzas de Arte Dramático, que todavía hoy, cincuenta años después, siguen sin resolver, pues la LOGSE las situará fuera del territorio de la tercera enseñanza en el que las situara la Ley Moyano, para pasar al de la segunda enseñanza, aunque el título que otorguen fuese equivalente a una licenciatura universitaria y ahora a un grado.

En esa dirección, los efectos de la LGE han sido más beneficiosos de lo que cabría esperar, y de lo que normalmente se reconoce, pues de una forma un tanto involuntaria, también traslada debates especialmente substantivos, como se dirá. A documentar y probar tales asertos dedicamos el presente trabajo.

\section{Del "giro expresivo" a la "expresión dinámica"}

Para Puelles Benítez el proyecto de Reforma que desemboca en la LGE, aúna la voluntad de "facilitar la adaptación, la consolidación y la continuidad del franquismo como régimen político" (2009, p.340), con la necesidad de "hacer frente a los problemas y exigencias de una sociedad inmersa en un proceso de profundo cambio económico, social y cultural, aunque no político" (p.343). Como señala Escolano, también se busca armonizar presupuestos humanistas y "personalistas con los requerimientos técnicos de una sociedad avanzada" (2002, p.174), y considera la LGE como "un aceptable intento de modernización de la estructura educativa" (p.174), o, mejor aún, un intento "relevante" (p.175). Valorando el tipo de Reforma posible en España, Ortega señala: 
En primer lugar, la que no pusiera en cuestión el régimen político en su conjunto. En segundo lugar, aquella que se mostrara bajo el signo de la modernidad y del progreso. En tercer lugar, la que contase con los adecuados respaldos de organismos internacionales competentes en educación (1992, p.37).

En la ideación técnica y pedagógica colaboran dos figuras prominentes. De un lado Díez Hochleitner, que en 1968 participa en la Conferencia Internacional sobre Planeamiento de la Educación, celebrada en París entre el 6 y el 14 de agosto. El documento con las Recomendaciones de tal Conferencia recoge palabras clave que definen el espíritu de la Reforma: formación integral, capital humano, igualdad de oportunidades, diagnóstico, renovación, innovación, experimentación o evaluación. En la apertura del IV Congreso Nacional de Pedagogía, celebrado entre el 30 de octubre y el 3 de noviembre de 1968, Díez Hochleitner proponía esas mismas ideas para abordar "los problemas educativos de suma importancia y urgencia que tiene planteados hoy nuestro país" (1969, p.67), derivados de lo que se definían como "exigencias que la previsible sociedad del futuro presentará a la educación" (Villar Palasí, 1969, p.10), lo que demandaba apertura a nuevas ideas.

Del otro, García Hoz, quien, como ocurrirá años después con el constructivismo y la LOGSE (Coll et al., 1993), será uno de sus "ideólogos" (Pozo Andrés, 2009), aportando una filosofía de la educación que informa cuantos documentos se generan, desde las Bases para un política educativa (1968) hasta las Orientaciones para la Educación General Básica, que destacan como la primera de sus innovaciones "una individualización del tratamiento educativo" (MEC, 1970b, p.4). Por ahí aparece la "educación personalizada", emparentada con el personalismo que promueven Maritain o Mounier, y que en España, de la mano de García Hoz, tendrá un sello particular. El personalismo tiene también entre sus primeros promotores a Ebner, quien en su programa "dialógico" formula la importancia del "tú" en la construcción del "yo", lo que pone en valor palabra y expresión (Caltagirone, 2017). Y asoma también la idea de creatividad y de persona creadora, dominante en los primeros capítulos de Educación Personalizada (1970), donde García Hoz formula ese "giro expresivo":

(...) toda relación humana es comunicación, toda comunicación requiere capacidad expresiva y comprensiva por parte del comunicante, de donde claramente se infiere que la educación personalizada, en la medida que responde a la apertura de la persona, desemboca en el desenvolvimiento de la capacidad comunicativa (1970, p.30).

Afirmará que la "educación deberá desarrollar en el hombre primordialmente su capacidad de comunicación, es decir, su capacidad expresiva y comprensiva” (1970, p.50)ํ․

No pretendemos abordar la genealogía del "giro", difícil de reconstruir, pero podemos señalar claves, si bien no siempre podamos discernir fuentes o influencias exactas que lo inspiran. En primer lugar, es relevante lo que se define como "filosofía de la persona" (Tusquets, 1960), corriente en la que situamos a Prohaska, que en 1961 publica su Pedagogía del encuentro, asentada en principios como "el medio entre el yo y el tú es la palabra" (1981, p.22)2, invocando diálogo y comunicación en el desarrollo de una persona que siente amenazada, pues: "lo personal se resiente de la presión de lo colectivo; el individuo ve frustrada la plena realización de sus características de unicidad e irrepetibilidad" (1981, p.7).

Una declaración que desgrana a continuación en ideas como libertad, apertura o alegría, tan relevantes al discurso de García Hoz (1970), cuando propone díadas fundamentales: singularidad/creatividad, autonomía/libertad, apertura/comunicación. En la construcción de la persona cobran centralidad palabra y expresión, la "dialogicidad" de Ebner o Freire, si bien el discurso de Paulo esté en las antípodas del personalismo de García Hoz, quien igualmente mantiene una prudente distancia con Mounier, más próximo a un activismo social y a una "transitividad crítica" que en España practican personas como José María de Llanos Pastor.

\footnotetext{
1 Cursiva en el original.
}

2 Cursiva en el original. 
La segunda línea a considerar en la apropiación del "giro expresivo", la tenemos en el desarrollo de una nueva forma de entender la educación artística, más atenta a los procesos, y que se manifiesta en toda Europa y América, con antecedentes en Creative Dramatics (1930) de Ward, Jeux Dramatiques dans l'Éducation (1936), de Chancerel, o Child Drama (1954) de Slade. En los primeros sesenta, emergen experiencias notables en Italia (Scabia y Casini-Ropa, 1978), Inglaterra (Bolton, 1984), Estados Unidos (Rosenberg, 1987) o Francia (Small, 1958; Dasté, Jenger y Voluzan, 1975), pero también en Argentina, con La expresión corporal y el niño (Stokoe,1967), o en España, con Carmen y María Aymerich o Ana Pelegrín, primeras voces en señalar la importancia de la expresión en el desarrollo armónico de la persona. En la referencia a la "expression libre" contenida en el título de la obra de Small, encontramos una invocación de la "no directividad" que persigue la liberación y el desarrollo de la espontaneidad y la originalidad.

En esa irrupción de la "expresión" en el currículo o en la animación sociocultural, influyen volúmenes como Techniques de l'expression (1964) de Dobbelaere y Saragoussi, o Pedagogía de la Expresión (1965), de Dobbelaere. El primero, publicado en castellano en 1974, incluye un prólogo de Carmen Aymerich, y esta escribe:

Ya sabemos la importancia que tiene hoy en día el hecho de poder crecer y proyectarse en una forma y estilo personales, como factor liberalizante del uniformismo y masificación que dominan en una gran mayoría de ámbitos sociales. Cada técnica de expresión... es un paso más hacia el dominio de sí mismo, hacia el conocimiento de los demás y hacia la comprensión y asimilación del mundo circundante (1974, p.7).

Reflexiones similares informan trabajos anteriores de Carmen y María Aymerich (1970), o de Baixas (1966), y en España cobra presencia el "paradigma" de la expresión, que supone una forma nueva de entender la presencia del arte en el currículo. Al mismo tiempo, se defiende un tratamiento unificado para las diferentes áreas de expresión:

(...) lo que hasta ahora se había conducido bajo la forma de ejercicios independientes entre sí -recitación, elocución, dibujo, pintura, danza, música, dramatización, etc.-, dirigidos a lograr unos resultados determinados al final de la ejecución, ahora se ha sistematizado, ordenado y globalizado. Y, sobre todo, se ha enfocado con una valoración totalmente distinta: no la del resultado final sino la del camino a seguir. Es precisamente en la trayectoria y no en el término..., donde radica el valor pedagógico de la expresión (Aymerich, 1974, p.8)

Para las hermanas Aymerich, tal expresión será "corporal, oral, plástica y musical" (1970, p.20), y formulan una "ley de concordancia", para "dar un sentido de unidad, de globalidad a las distintas actividades que forman la expresión artística y hacerlas confluir en unos mismos objetivos" (p.26), y se promueve la globalización defendida por García Hoz (1970, p.47). Baixas, por su parte, no orienta la expresión hacia la formación de artistas, sino como "forma de abrirse, de conocer su interior y de manifestarlo a los demás" (1967, p.14), de "descubrir a sus semejantes y de vivir en comunión con ellos" (p.14).

Todo ello está en plena sintonía con lo que Marinis definió como "el sesenta y ocho teatral", que propone un uso del teatro como "instrumento... de intercomunicación y conocimiento mutuo..., para lograr la autosatisfacción de necesidades sociales y existenciales" (1988, p.279). En la misma dirección, interesan las aportaciones del movimiento del happening o la performance (Goldberg, 1988), con su énfasis en la superación de los roles de creador y receptor, o la emergencia del paradigma de la "democracia cultural" que defiende un nuevo sujeto en la acción cultural (MC, 1979). Y no cabe olvidar, en ningún caso, el soporte teórico de la Internacional Situacionista, en su crítica al espectáculo y en su defensa de la situación y del proceso (Puchner, 2004). En estas líneas de trabajo cobra importancia creciente un nuevo sujeto creador ajeno al estatus del artista y más próximo a la posición del activista, y que se define en la famosa frase de Boal "todo mundo pode fazer teatro - até mesmo os actores!" (1978, p.18) ${ }^{3}$, que ya formulara Moreno en su teatro de la espontaneidad (1947).

3 En castellano: "todo el mundo puede hacer teatro, jincluso los actores!" (traducción propia). 
En la LGE el "giro" se plasma en la "expresión dinámica", área curricular nueva, que García Hoz crea ex nihilo y ad hoc, y que justifica en función del "dinamismo de la educación personalizada", en tanto la persona es una "realización imperfecta proyectada hacia la perfección pura" (1970, p.22). Frente al mecanicismo y al materialismo, y frente a las "adquisiciones estáticas" (1970, p.47), el término "dinámica", quiere vincularse al "dinamismo" que emerge de la obra de Bergson o Whithead, que tanto insisten en imprimir tal carácter en la educación, como esfuerzo creador (Abbagnano y Visalberghi, 1988) y con carácter procesual. García Hoz considera cuatro áreas en el contenido cultural de la educación, que define como expresión verbal, numérica, plástica y dinámica, y propone un lenguaje dinámico, que incluiría gesto, movimiento y danza, y en el que "el sistema de signos utilizado está constituido en gran parte por el propio organismo del sujeto que expresa" (1970, p.53), pues la educación debe activar y movilizar la fuerza expresiva de la persona. De la dimensión del área darán cuenta las Orientaciones pedagógicas, que señalan que sus objetivos "se confunden con los objetivos mismos de la educación" en el desarrollo de "percepción, atención, curiosidad, sensibilidad", pero también "espontaneidad, expresividad, naturalizad y creatividad" (MEC, 1970b, p.22). Póveda la definirá como un "lenguaje total", en el que considera los aspectos psicofísicos y dramáticos, en una interesante lectura desde la ribera dramática (1977, p.7).

La apuesta de García Hoz por un giro expresivo en la cultura científica, se traslada a la cultura normativa en las Orientaciones, que definen con mayor precisión el concepto y alcance de Expresión Dinámica (ED), y se dirá que "puede englobar la educación del movimiento, ritmo, expresión corporal, mimo, dramatización, juegos, gimnasia, deportes, música, etc." (MEC, 1970b, p.22), aunque finalmente se consideren la "formación musical" y la "educación física y deportiva" (MEC, 1970b, p.47), que por su carácter instrumental harán uso de actividades como:

, Interpretaciones libres de ejercicios de expresión del gesto.

, Mimos y pantomimas.

, Dramatización de cuentos, leyendas.

, Teatro guiñol.

> Teatro infantil, representación en grupo.

> Lecturas dramatizadas con fondo musical (MEC, 1970b, p.24).

La enumeración, leída con los ojos de hoy, presenta un galimatías conceptual, en tanto se trata, en la perspectiva de la educación teatral, de diferentes disciplinas, lo cual denota uno de los problemas centrales del momento: la ausencia de una cultura científica propia en educación teatral. Pese a todo, supondrá un avance, considerando el currículo entonces vigente, en el que la dimensión expresiva en la educación estaba ausente. En disciplinas como Educación Física, la propuesta facilita que esta incorpore, al menos sobre el papel, ámbitos como expresión corporal, ritmo, danza, o movimiento expresivo, que dan sentido al giro. La educación teatral asoma tímidamente en uno de sus procedimientos, la dramatización, que se convierte en herramienta para la didáctica de otras áreas de expresión como la de Lenguaje, al proponer actividades como "dramatizaciones", "adaptaciones teatrales" o escribir "escenas teatrales" (MEC, 1970b, p.11). No estamos ante una incorporación de la educación teatral, como tal, al currículo, pero sí ante una propuesta de educar por el teatro.

Se abre un sendero que se amplía, al amparo de la LGE, en los primeros ochenta, cuando el Ministerio promueva una actualización curricular con los Programas Renovados, y asoma, como área ya diferenciada, la "dramatización", aunque también se utilice el término "juego dramático". Si bien no llegarían a implementarse plenamente (Tejerina, 1994), supusieron una oportunidad para ahondar en el desarrollo curricular en educación teatral, determinando finalidad, objetivos, contenidos, evaluación o metodologías, y esa cultura se consolidará y ampliará con la LOGSE. Del mismo modo, los Programas Renovados, como ya ocurría con las Orientaciones de 1970, potencian el carácter instrumental, metodológico, de los recursos dramáticos en la didáctica de diferentes áreas, con lo que cobra fuerza la idea antedicha de educar por el teatro (Vieites, 2014). 
Así, entre la LGE y la LOGSE se establecen continuidades en educación teatral, y los primeros ochenta y noventa suponen una puesta en valor de la misma, aunque en su dimensión aplicada la propuesta pierda peso. En efecto, la realidad empírica demostrará que al hablar de educación artística en EGB (LGE), o en Primaria (LOGSE), se está hablando en realidad de Expresión Plástica y Expresión Musical, quedando la dramatización o el juego dramático en muy segundo plano, porque ni el profesorado de EGB ni el profesorado de Primaria había recibido, salvo alguna excepción, una formación específica y pertinente, inicial o permanente, por parte de la administración educativa (Tejerina, 1994; Motos, 2020), lo que sigue siendo una de las muchas asignaturas pendientes en nuestro sistema educativo.

En el BUP, la LGE incluirá las denominadas Enseñanzas y Actividades Técnico-Profesionales (EATP), a partir de la Orden del 22 de marzo de 1975 (BOE del 18 de abril). La denominada "Teatro y expresión corporal", que suponía dos horas de clase a la semana durante un curso escolar, se establece en la Orden del 18 de abril de 1985 (BOE del 27 de abril), debiendo ser autorizada por la Dirección General correspondiente (Lamapereira y Riobó, 1997). Con ello, la educación teatral general y aquella con una dimensión más propedéutica, emergían por primera vez en la historia del sistema educativo español (Buezo, 1994).

No obstante, esta tímida incorporación de la educación teatral al currículo no fue acompañada, como se dijo, de medidas orientadas a la formación permanente del profesorado ni a su cualificación inicial, ni tampoco a facilitar la formación de expertos en cada centro, al menos en los años de implantación de Preescolar, EGB o BUP. Será en los Movimientos de Renovación Pedagógica (Mata, 1984), como Escola de Mestres Rosa Sensat o Acción Educativa, o en la Escola d'Expressió i Psicomotricitat de Barcelona, y en Escuelas de Verano, seminarios y grupos de trabajo, donde se lleven a cabo importantes iniciativas de formación y actualización docente (Motos, 2020).

\section{La educación teatral superior}

La LGE se proponía paliar los "defectos estructurales" del sistema educativo (Villar Palasí, 1969, p.9), dando a la Reforma "un sentido integral que abarque todos los grados y modalidades de la educación" (Hochleitner, 1969, p.69), pues desde la Ley Moyano de 1857 había transcurrido más de un siglo, por mucho que se hubiese actualizado con modificaciones y ajustes (MEC, 1969). Y un capítulo importante lo constituían un conjunto diverso de enseñanzas, entre las que se encuentran las artísticas (y en ellas las superiores, como artes plásticas, arte escénico, música o danza), a las que el Libro Blanco dedica el capítulo 6, justo después del bloque de la Enseñanza Superior, en ningún caso en el de la Enseñanza Media.

Si bien presentaban una cierta heterogeneidad, algunas estaban situadas, en su ordenación académica y desde su implantación, en el ámbito de la "tercera enseñanza", y se impartían en escuelas especiales. Por tanto, el Libro Blanco no deja de considerar "superiores" a los centros que las imparten, como las "Escuelas Superiores de Arte Dramático", o señalar deficiencias diversas en la organización de los estudios "por falta de dotaciones presupuestarias" (MEC, 1969, p.108), y en consecuencia apuntar que los estudios de Arte Dramático y Danza "necesitan urgentemente el establecimiento de un sistema docente suficientemente diversificado" (MEC, 1969, p.110). También es relevante la consideración de la relación alumnado-profesorado en las enseñanzas artísticas, que se entiende ha de ser acorde con su naturaleza, "por su carácter eminentemente práctico y por el respeto debido a la personal libertad creadora", pues "cada alumno necesita una orientación y una corrección personales", con lo que "si se quiere que la enseñanza sea eficaz, el incremento del alumnado debe ir necesariamente acompañado de un paralelo y proporcional aumento de profesores" (MEC, 1969, p.111).

Tras el diagnóstico, la LGE, en consonancia con el carácter superior de estas y otras especialidades de estudios y escuelas, y con algún trabajo publicado entonces (Castro, 1969), establece en la disposición transitoria segunda su incorporación a la Universidad. Entre ellas, las Escuelas Normales y las Escuelas de Arquitectura Técnica e Ingeniería Técnica, el Instituto Nacional de Educación Física, los estudios de Periodismo, o las Escuelas Superiores de Bellas Artes, los Conservatorios de Música 
y las Escuelas de Arte Dramático (MEC, 1970a). Conviene resaltar la importancia de esta disposición, pues con la misma tónica, la Ley Orgánica de Reforma Universitaria, en su disposición adicional 5, mantenía abierta tal posibilidad para los centros en que fuese pertinente su integración en una universidad en razón de las titulaciones ofertadas (MEC, 1983). Todo ello ha permitido que más recientemente se incorporen a la Universidad estudios de Comercio, Marina Civil, Enfermería o Relaciones Laborales. A día de hoy quedan fuera de la ordenación universitaria, los estudios superiores de Arte Dramático, Danza, Diseño, Conservación y Restauración de Bienes Culturales o Música, que imparten centros superiores de enseñanzas artísticas, con todas las problemáticas que ello genera, a las que se suma el que en los últimos años numerosas universidades, públicas y privadas, hayan comenzado a ofrecer estudios de grado y postgrado en tales especialidades, con la desigual competencia que ello genera.

La incorporación de las enseñanzas superiores de Arte Dramático a la Universidad, junto a otras titulaciones superiores, suponía la ordenación, plena y definitiva, del campo de la tercera enseñanza, en sintonía con lo que ocurría en Europa (Embid, 1997; Marzal, 2010; Vieites, 2015a), y abría perspectivas de nuevos desarrollos para tales enseñanzas, en su regularización académica y en el campo de la investigación, una posibilidad ni calibrada suficientemente (Turina, 1994) ni objeto de debate o consideración crítica en revistas especializadas, en aquel momento. Habrá que esperar a finales de los ochenta para que se genere un movimiento importante a favor de la integración de las enseñanzas artísticas superiores en la Universidad, especialmente desde los Conservatorios Superiores de Música (Vieites, 2020a), que será especialmente relevante en los inicios del siglo XXI (Hervás, 2010). Las consecuencias del incumplimiento de la norma, han sido analizadas en trabajos diversos (Marzal, 2012; Pastor, 2012; Carrera Ramírez, 2014; González Martínez, 2015), en los que se valoran las dificultades de adecuación efectiva al Espacio Europeo de Educación Superior (Vieites, 2016), o en el desarrollo de la investigación (Vieites, 2015b). A día de hoy, cincuenta años después, sigue siendo un problema de ordenación educativa por resolver.

\section{Educación teatral y cultura científica}

La cultura normativa emanada de la LGE tendrá repercusión en la cultura normativa generada en otras instancias, vinculadas o dependientes del Ministerio, fundamentalmente en las Escuelas Normales y en los Institutos Nacionales de Educación Física, donde se inicia la incorporación a su currículo de contenidos, o disciplinas, vinculados con la expresión corporal, la danza, o el movimiento expresivo. El constructo "expresión dinámica" suponía una invitación a una ampliación de dominios, y así, en las Escuelas Universitarias de Formación del Profesorado en la hora de crear departamentos de didácticas específicas, el sintagma "expresión corporal" prevalecerá frente al de "educación física, en denominaciones como "Departamento de Didáctica de expresión musical, plástica y corporal". Se configuran entonces dos tradiciones docentes e investigadoras vinculadas con la Expresión Corporal que se han venido desarrollando en las actuales Facultades de Educación (Mula Franco, 1984) y en las Facultades de Ciencias del Deporte y de la Educación Física (Coterón López y Gil Ares, 2012). Pero del mismo modo, y desde las actuales Facultades de Educación, considerando la polisemia del término teatro, se pone en marcha un importante trabajo docente e investigador vinculado con la dramatización, con profesorado de departamentos de Didáctica de la Lengua y la Literatura, como Isabel Tejerina.

En todo ese proceso han quedado un tanto al margen las Escuelas Superiores de Arte Dramático, porque al no integrarse en la Universidad su cultura investigadora no será una prioridad y su foco de atención se dirige a la formación de artistas y no de educadores teatrales. Con todo, Motos recuerda que tanto en la Real Escuela Superior de Arte Dramático de Madrid (curso 70-71), como en el Instituto del Teatro de Barcelona (curso 72-73), se realizan cursos para profesorado de Preescolar y EGB, en ocasiones en colaboración con Institutos de Ciencias de la Educación (2020, pp.124-125). Estamos ante un escenario que se formula y no se explora, pues aún en las conclusiones de las 
"Primeras Jornadas de Estudio sobre Teatro Escolar, Teatro para Niños y Teatro de Títeres", celebradas en Madrid del 30 de mayo al 4 de junio de 1977, organizadas por el Instituto Nacional de Ciencias de la Educación, se señalaba, en la propuesta número 4, que la "formación de profesionales capacitados para desarrollar en condiciones óptimas la práctica teatral en el medio escolar, debe contemplar aspectos psicopedagógicos y teatrales", y que esa formación debería constituir "el plan de estudios de una futura especialidad en «Pedagogía teatral» a impartir en Escuelas Universitarias de Formación del Profesorado, en los solicitados «Centros Dramáticos» y en los Institutos del Teatro" (Arroyo, 1978, p.34). La puesta en marcha de esa especialidad de estudios, que existe países como Argentina, Brasil o Colombia, exigiría que los Ilamados "Institutos del Teatro", es decir, Escuelas Superiores de Arte Dramático, se hubiesen integrado en la Universidad, como las Escuelas Normales, lo que sin duda permitiría construir un marco de desarrollo a medio camino entre las "ciencias" del teatro y las ciencias de la educación, sumamente beneficioso en direcciones diferentes.

En el campo de la cultura empírica, se desarrollan muchas iniciativas que solo ocasionalmente se dan a conocer en revistas educativas o en publicaciones científicas. Como apoyo fundamental destaca la labor de los Movimientos de Renovación Pedagógica, que promueven la publicación de materiales, como puede ser el caso del volumen Encuentro Teatro y Educación (1984), patrocinado por el MEC, o Teatro aula. Aula teatro, que edita Acción Educativa (1988), que ofrecen un magnífico muestrario del quehacer empírico y de la reflexión teórica y metodológica que le acompaña. De igual modo, revistas como Cuadernos de Pedagogía prestarán atención creciente al campo del teatro escolar.

En el ámbito de la cultura científica emergen tres grandes ámbitos. En primer lugar, trabajos con una orientación histórica que señalan la genealogía y desarrollo de una determinada tradición, como la del teatro escolar (Cervera, 1982); en segundo lugar trabajos con una orientación metodológica, centrados en explicar el hacer (Fernández y Malonda, 1978), y finalmente los que poseen una orientación más teorética (Póveda, 1973; Eines y Mantovani, 1980; Mantovani, 1980; Santiago, 1985). En España fue particularmente notable el segundo de los ámbitos, tanto en producción propia como en obra traducida. Se editan títulos que, acompañados de reflexiones teóricas, ofrecen un número importante de actividades para el quehacer diario, y así podemos destacar El mim (1974), de Antón Font; Expresión corporal (1976), de Ángeles Alonso; Psicomotricidad, ritmo y expresión corporal (1980), de Marta Schinca; Como practicar la dramatización con niños de 4 a 14 años (1981), de Juan Cervera, o Actuar para ser (1984), de José Cañas. En cuanto a textos traducidos, se publican títulos como Yo soy el árbol (tú el caballo) (1976), de Passatore, Destefanis, Fontana y De Lucis; Expresión dramática infantil ([1954] 1978), de Slade; Juegos de actuación dramática (1979), de Freudenreich, Grässer y Köberling; Juego y aprendizaje (1980), de Coburn-Staege, o Improvisación ([1974] 1982), de Hodgson y Richards. Junto a estos trabajos, y a medio camino entre la cultura empírica y la científica, cabría situar numerosos manuales escolares de Expresión Dinámica, muchos de ellos centrados en la música y la educación física.

Estamos ante uno de los mayores logros de aquella tímida apuesta de la LGE o de las expectativas que generan los Programas Renovados, dado que la producción editorial vinculada a la educación teatral aumenta de forma sostenida (Romera, 1994), y comienzan a formularse debates interesantes, con lo que el campo cobra profundidad y amplitud muy especialmente en la eclosión de los noventa (Motos y Tejedo, 1987; Cañas, 1992; Póveda, 1995; Bercebal, 1995). En muchos trabajos se deja sentir un progresivo abandono de la casa común de la "expresión dinámica", y una apuesta por explorar las especificidades de cada ámbito de expresión; cobran fuerza conceptos como "dramatización", "juego dramático" o "dramática creativa", aunque ya desde 1966 con Joan Baixas asoma el de "expresión dramática", tan querido a Barret (1979), y se articula un debate conceptual que llega a nuestros días sin estar resuelto, pues como señala Motos, estamos todavía ante "un conjunto de prácticas cuya delimitación no está bien establecida" (2020, p.19). 
En la generación de cultura científica propia del campo del teatro en educación, destaca el papel de las Facultades de Educación, donde se han defendido memorias de licenciatura o de doctorado (Póveda, 1974; Motos, 1992; Núñez Cubero y Navarro Solano, 2007). El desarrollo de la investigación en especialidades de estudio que incorporan materias como "expresión corporal" o "dramatización" al currículo, como las titulaciones en Magisterio o Educación Física, es un síntoma de lo que supuso para escuelas y titulaciones su incorporación a la Universidad. Sin embargo, el aporte realizado desde las ESAD ha sido inferior, pese a que buena parte de su alumnado inicie su actividad profesional en el campo de la educación teatral no formal. Actualmente el número de revistas científicas propias del campo del Arte Dramático en España es reducido, y en el portal DICE no cuenta siquiera con apartado propio, como sí ocurre en Didáctica de la Expresión Corporal o en Educación Física y Deportiva.

Las razones por las que tales especialidades y los centros que las imparten (también música, danza o diseño), no se incorporan a la Universidad a partir de 1970, son diversas, aunque los efectos son devastadores, porque la LOGSE las situará en el territorio de la Enseñanza Media, quedando los centros y su profesorado anclados en la educación secundaria, con la imposibilidad de dar sentido a disposiciones contenidas en la propia LOGSE como el desarrollo de estudios propios de doctorado en colaboración con las universidades y el impulso a una investigación propia y específica (Vieites, 2020b). En efecto, uno de los ámbitos que presenta un mayor déficit es el campo de la investigación, prioridad del Libro Blanco. Todavía hoy la norma que regula a nivel estatal los estudios superiores de Arte Dramático establece que:

Los centros de enseñanzas artísticas superiores de Arte dramático fomentarán programas de investigación científica y técnica propios de esta disciplina, para contribuir a la generación y difusión del conocimiento y a la innovación en dicho ámbito. Las Administraciones educativas establecerán los mecanismos adecuados para que estos centros puedan realizar o dar soporte a la investigación científica y técnica, que les permita integrarse en el Sistema Español de Ciencia y Tecnología (MEC, 2010, p.48468).

Resulta difícil dar sentido a tal mandato cuando ni las escuelas ni los conservatorios están reconocidos como centros de investigación y cuando el perfil de su profesorado tan solo contempla carrera docente, no investigadora. En esa dirección la LGE promueve una medida que podría haber supuesto la plena convergencia con Europa en la ordenación de las EEAASS, dado que en ese espacio geográfico, como también en el resto del planeta, o son universitarias o están adscritas a una universidad (Marzal, 2008). Y por eso mismo toda la legislación posterior (LOGCE, LOCE, LOE, LOMCE) implica un retroceso.

Además del giro expresivo, la LGE también formula un "giro pedagógico", y se defiende la formación pedagógica del profesorado, al señalar como necesario "el perfeccionamiento constante..., de tal modo que se halle siempre al día de las corrientes artísticas y de las nuevas técnicas didácticas", y que "los cursos de perfeccionamiento..., siempre útiles, resultan aquí indispensables" (MEC, 1969, p.111). Curiosamente esa apuesta por el perfil bifronte del profesorado (formación cultural y artística más formación pedagógica) desaparece tras la Ley Orgánica de Educación (LOE). El Real Decreto 276/2007, que aprueba el Reglamento de acceso a los cuerpos docentes referidos en la LOE, establece que para acceder a las especialidades docentes del Cuerpo de Profesores o Catedráticos de Música y Artes Escénicas:

Con la excepción de quienes ingresen en el cuerpo en especialidades propias de Arte Dramático, estar en posesión de la formación pedagógica y didáctica a la que se refiere el artículo 100.2 de la Ley Orgánica 2/2006, de 3 de mayo, de Educación (MEC, 2007, pp.8919-8920).

Lo cual viene a decir que para impartir docencia en una Escuela Superior de Arte Dramático, no será necesaria formación pedagógica alguna. De nuevo asoman los retrocesos. Pero estos 
también se dejan sentir en el campo de la educación teatral general. La tímida apuesta de la LGE, que adquiere entidad con los Programas Renovados de 1981 y 1982, y sigue desarrollando la LOGSE (Tejerina, 1994; Motos, 2020), desaparece con la Ley Orgánica de Calidad de la Educación (LOCE), pero también con la LOE.

Tras cincuenta años, y en educación teatral, sea general o especializada, hemos vuelto al punto de partida. De nuevo necesitamos un "giro expresivo", en la educación general, y la incorporación a la Universidad en la especializada, también para el pleno desarrollo de la Pedagogía Teatral y una formación consecuente de profesorado de teatro.

Quedan cuestiones por abordar para calibrar el alcance real de la LGE en el fomento de la educación teatral en España, todas con incidencia en el momento actual; entre ellas señalamos:

, La genealogía, desarrollo y orientaciones del "giro expresivo", y su incidencia en las prácticas educativas vinculadas con la expresión y la educación artísticas (Trombetta, 1977).

> La construcción del área denominada "expresión dinámica" (Póveda, 1977), y el estudio de sus manifestaciones científicas y empíricas, prestando atención a la producción editorial.

, El estudio de lo que ha sido el desarrollo curricular de la educación teatral general en los Programas Renovados de los ochenta y en la EATP de Teatro, y las culturas científica y empírica que generan.

, La progresiva exploración y desarrollo de la dimensión más educativa del teatro de escolares, como práctica no formal (Heráns y Patiño, 1983).

, Los proyectos, procesos, tiempos y espacios para la formación del profesorado en una perspectiva formal y no formal.

> La emergencia de los diferentes ámbitos de la educación teatral como prácticas educativas, sea dramatización, juego dramático, expresión corporal, mimo, teatro de objetos, o el propio teatro escolar como teatro de escolares. Y en cada caso las culturas científica, empírica (y metodológica), que presentan una notable producción editorial, también en obra traducida. Aquí cobra relevancia la cuestión terminológica, planteada por Barret (1977) o Courtney (1987).

> El desarrollo de la educación teatral superior, y de la normativa para la ordenación de los estudios superiores de Arte Dramático, en una perspectiva comparada con otros países.

, La producción científica de las Escuelas Superiores de Arte Dramático, Escuelas de Magisterio, Institutos Nacionales de Educación Física u otros centros superiores.

, La bibliografía manejada en la producción científica propia, o como base y fundamento de la cultura empírica.

, El análisis del rol que se le asigna a la educación teatral en Preescolar, EGB y BUP, vinculada con la educación integral o la profesional.

, El estudio comparado entre lo que propone la LGE, la LOGSE y otras leyes de educación como la LOCE o la LOE en relación a la educación teatral, para considerar avances y retrocesos.

, La emergencia de la Pedagogía teatral entendida como ciencia de la Educación teatral.

Estamos ante una línea de investigación centrada en la educación teatral en toda la diversidad del sintagma, considerando sus culturas, en su desarrollo histórico y en una perspectiva comparada, y que abarca un período fundamental en nuestra historia educativa reciente, que va de finales de los sesenta a los primeros noventa, cuando la educación teatral en España, en su conjunto, vive 
un desarrollo notable. Una línea que en su continuidad hasta el momento actual seguramente indicará caminos por hacer para lograr que la educación teatral desarrolle todo su potencial, porque, como dijera Cañas (1984), aprendiendo a actuar, aprendemos a ser, y nada puede ser más importante, como recuerda Morin (2016).

\section{Referencias}

Abbagnano, N. y Visalberghi, A. (1988). Historia de la pedagogía. Fondo de Cultura Económica.

Amich, M., Heráns, C., Lara, J. y Tejerina, L. (1983). Teatro, imagen, animación. Laia.

Arroyo, J. (1978). Teatro escolar/Teatro para niños. Noticia de unas jornadas. Pipirijaina, 6, 33-36.

Aymerich, C. (1974). Prólogo a la edición española. En G. Dobbelaere y P. Saragoussi, Técnicas de expresión (pp. 7-8). Oidá.

Aymerich, C. y Aymerich, M . (1970). Expresión y arte en la escuela 1. Teide.

Baixas, J. (1967). Juegos de expresión. Hogar del libro.

Barret, G. (1979). Expression dramatique. Plaidoyer por une terminologie ouverte. Jeu, Revue de théâtre, 12, 254-260.

Bercebal, F. (1995). Drama. Ñaque.

Boal, A. (1978). Duzentos e tal exercícios e jogos para o actor e o não actor com ganas de dizer algo a través do teatro. SCARL.

Bolton, G. (1984). Drama as education. Longman.

Buezo, C. (1994). La enseñanza del teatro en los centros de secundaria. De la dramatización a la E.A.T.P. de teatro. Teatro, Revista de Estudios Teatrales, 5, 241-252.

Caltagirone, C. (2017). A relação Eu-Tu em Ferdinand Ebner. Conjectura, 22(3), 409-419.

Cañas, J. (1984). Actuar para Ser. Fundación Paco Natera.

Cañas, J. (1992) Didáctica de la expresión dramática. Octaedro.

Carrera Ramírez, F. (2014). Una plataforma muy estable. Danzaratte, 8, 77-93.

Castro, R. (1969). Incorporación de los conservatorios o escuelas superiores de música a la universidad. Cuadernos de actualidad artística, 6, 42-52.

Cervera, J. (1982). Historia crítica del teatro infantil español. Editora Nacional.

Cervera, J. y Guirau, A. (1972). Teatro y educación. PPC.

Coll, C., Martín, E., Mauri, T., Miras, M., Onrubia, J., Solé, I. y Zabala, A. (1993). El constructivismo en el aula. Graó.

Coterón López, J. y Gil Ares, J. (2012). La Expresión Corporal en los estudios de Ciencias de la Actividad Física y del Deporte. En G. Sánchez y J. Coterón (Eds.), La expresión corporal en la enseñanza universitaria (pp. 43-57). Universidad de Salamanca.

Courtney, R. (1987). Dictionary of Developmental Drama. Charles C. Thomas.

Dasté, C., Jenger I, y Voluzan, J. (1975). L'enfant, le théâtre, l'école. Delachaux et Niestlé. 
Díez Hochleitner, R. (1969). Conferencia. Revista de Educación, 201, 66-69.

Eines J. y Mantovani, A. (1980). Teoría del juego dramático. MEC.

Embid, A. (1997). Informe sobre la conveniencia de promulgar una Ley Orgánica Reguladora de la Organización en Régimen de Autonomía de las Enseñanzas Artísticas Superiores en España. ACESEA. https://bit.ly/2Gt62IJ

Escolano, A. (2002). La educación en la España contemporánea. Biblioteca Nueva.

Fernández, R. y Malonda, A. (1978). Juegos de dramatización. Santillana.

García Hoz, V. (1970). Educación personalizada. CSIC.

Goldberg, R. (1988). Performance Art: From Futurism to the Present. Thames \& Hudson.

González Martínez, F. (2015). Conservatorios superiores de música: el drama de la memoria en un escenario de crisis globalizada. Revista Internacional de Educación Musical, 3, 51-58.

Graells, G.-J. (1990). L'Institut del Teatre. 1913-1988. Historia gràfica. Diputació de Barcelona.

Granda, J. (1994): Historia de una escuela centenaria. RESAD.

Heráns, C. y Patiño, E. (1984). Teatro y escuela. Laia.

Hervás, V. (2010). Un Manifiesto que avanza decididamente hacia el futuro. https://bit.ly/32cVIfv

Lamapereira, A. y Riobó, P. P. (1997). Contextos e particularidades da EATP de Teatro. Revista Galega de Educación, 28, 22-24.

Mantovani, A. (1980). El teatro, un juego más. Nuestra Cultura.

Marinis, M. (1988). El nuevo teatro, 1947-1970. Paidós.

Marzal, C. R. (2008). El régimen jurídico de las enseñanzas musicales en España [tesis doctoral, no publicada].

Marzal, C. R. (2010). El régimen jurídico de las enseñanzas musicales. Diputación de Valencia.

Marzal, C. R. (2012). Las enseñanzas artísticas superiores en el sistema educativo general. Justicia administrativa, 57, 43-74.

Mata, M. (1984). Renovación pedagógica. Aldaba, 2, 45-60.

Ministerio de Cultura (1979). Hacia una democracia cultural. Ministerio de Cultura.

Ministerio de Educación y Ciencia (1969). La educación en España. Bases para una política educativa. MEC.

Ministerio de Educación y Ciencia (1970a, 6 de agosto). Ley 14/1970, de 4 de agosto, General de Educación y Financiamiento de la Reforma Educativa. Boletín Oficial del Estado, 187, 12525-12546. https://bit.ly/2HYj6pN

Ministerio de Educación y Ciencia (1970b). Orientaciones pedagógicas para la educación general básica. https://bit.ly/3kNzO9X

Ministerio de Educación y Ciencia (1983, 25 de agosto). Ley Orgánica 11/1983, de 25 de agosto, de Reforma Universitaria. Boletín Oficial del Estado, 209, 24034-24042. https://bit.ly/32dF0N6 
Ministerio de Educación y Ciencia (2007, 23 de febrero). Real Decreto 276/2007, de 23 de febrero, por el que se aprueba el Reglamento de ingreso, accesos y adquisición de nuevas especialidades en los cuerpos docentes a que se refiere la Ley Orgánica 2/2006, de 3 de mayo, de Educación, y se regula el régimen transitorio de ingreso a que se refiere la disposición transitoria decimoséptima de la citada ley. Boletín Oficial del Estado, 53, 6-43. https://bit.ly/36aJfdM

Ministerio de Educación y Ciencia (2010, 14 de mayo). Real Decreto 630/2010, de 14 de mayo, por el que se regula el contenido básico de las enseñanzas artísticas superiores de Grado en Arte Dramático establecidas en la Ley Orgánica 2/2006, de 3 de mayo, de Educación. Boletín Oficial del Estado, 137, 48467-48479. https://bit.ly/3mYzOVz

Moreno, J. L. (1947). The theatre of spontaneity. Beacon House.

Morin, E. (2016). Aprender a ser. Paidós.

Motos, T. (1992). Las técnicas dramáticas. Procedimiento didáctico para la enseñanza de la lengua y la literatura en la educación secundaria [tesis doctoral, no publicada].

Motos, T. (2020). Teatro en la educación (España, 1970-2018). Octaedro.

Motos, T. y Tejedo, F. (1987). Prácticas de dramatización. Humanitas.

Mula Franco, A. (1984). Educación del cuerpo en la EGB. Anales de la Universidad de Alicante. Escuela de Magisterio, 2, 91-103.

Núñez Cubero, L. y Navarro Solano, Ma . R. (2007). Dramatización y educación: aspectos teóricos. Teoría de la educación, 19, 225-252. https://doi.org/10.14201/3262

Ortega, F. (1992). Las ideologías de la reforma educativa de 1970. Revista de Educación, Nºxtra, 31-46.

Pastor, P. (2012). La música a la universidad: por la integración en la universidad de las enseñanzas artísticas superiores. Eufonía. Didáctica de la música, 56, 52-70.

Póveda, D. (1973). Creatividad y teatro. Narcea.

Póveda, D. (1974). La expresión dramática en el contexto de una programación educativa. [tesis doctoral, no publicada].

Póveda, D. (1977). Expresión dinámica. Un lenguaje total. Narcea.

Póveda, D. (1995). Ser o no ser. Reflexión antropológica para un programa de pedagogía teatral. Narcea.

Pozo Andrés, M. M. (2009). Teorías educativas personalistas. En M. M. del Pozo Andrés (Ed.), Teorías e instituciones contemporáneas de educación (pp. 267-289). Biblioteca Nueva.

Prohaska, L. (1981). Pedagogía del encuentro. Herder.

Puchner, M. (2004). Society of the Counter-Spectacle: Debord and the Theatre of the Situationists. Theatre Research International, 29(1), 4-15. https://doi.org/10.1017/S0307883303001214

Puelles Benítez, M. (2009). Evolución de la educación en España durante el franquismo. En A. Tiana, G. Ossenbach y F. Sanz (Coords.), Historia de la educación [Edad Contemporánea] (pp. 329-349). UNED.

Romera Castillo, J. (1995) Un repertorio bibliográfico sobre la enseñanza del teatro. Teatro, Revista de Estudios Teatrales, 5, 253-264. 
Rosenberg, H. S. (1987). Creative Drama and Imagination. CBS College Publishing.

Rubio Jiménez, J. (2002). Los tratados de declamación y las enseñanzas teatrales en los siglos XVIII y $\mathrm{XIX}$. ADE/Teatro, 92, 120-129.

Santiago, P. (1985). De la expresión corporal a la comunicación interpersonal. Narcea.

Scabia G. y Casini-Ropa, E. (1978). L'animazione teatrale. Guaraldi.

Small, M. (1958). L'enfant et le jeu d'expression libre. Delachaux \& Niestlé.

Soria Tomás, G. (2010). La formación teatral en España. La Real Escuela Superior de Arte Dramático (1831-1857). Fundamentos.

Tejerina, I. (1994). Dramatización infantil. Siglo XXI.

Trombetta, C. (1977). Le attività espressive. Le Monnier.

Turina, J. L. (1994). El estado actual de las enseñanzas de música, danza y arte dramático. Arte, Individuo y Sociedad, 6, 87-104.

Tusquets, J. (1960). Exposición y crítica de la nueva catequética. Revista de Educación, 120, 473-477.

Vieites, M. F. (2014). Educación teatral: una propuesta de sistematización. Teoría de la educación, 33, 77-101. https://doi.org/10.14201/teoredu201426177101

Vieites, M. F. (2015a). Arte dramático y universidad pública: hacia una integración necesaria. Profesorado: Revista de currículum y formación del profesorado, 19(1), 555-573. https://bit.ly/3fDqJPt

Vieites, M. F. (2015b). La investigación teatral en una perspectiva educativa: retos y posibilidades. Educatio siglo XXI, 33(2), 11-30. http://dx.doi.org/10.6018/j/232671

Vieites, M.F. (2016). Las enseñanzas artísticas superiores y el Espacio Europeo de Educación Superior en España. Una lectura crítica. Revista Complutense de Educación, 27(2), 499-516. https://doi. org/10.5209/rev_RCED.2016.v27.n2.46540

Vieites, M. F. (2020a). Las enseñanzas artísticas superiores en la ordenación educativa en España. Una visión crítica. Foro de Educación, 18(1), 209-23. https://doi.org/10.14516/fde.676

Vieites, M. F. (2020b, 14 de octubre). Enseñanzas Artísticas Superiores: Volver a la LOE, volver a casa [ponencia]. Conservatorio Superior de Danza de Málaga. Danzaratte, 13, 68-84.

Villar Palasí, J. L. (1969). Introducción. Revista de Educación, 201, 7-10. 